\title{
Multihazard Mapping of Banepa and Panauti Municipalities
}

\author{
Laxmi Thapa ${ }^{1}$, Shrijana Panta ${ }^{2}$, Sanjeev Kumar Raut ${ }^{1}$, Florencia Matina Tuladhar ${ }^{3}$ \\ Janak Raj Joshi ${ }^{4}$, Nawaraj Shrestha ${ }^{5}$, Prashant Ghimire ${ }^{6}$, Anish Joshi ${ }^{7}$ \\ ${ }^{1}$ Survey Officer, Survey Department, Nepal, thapalaxmi278@gmail.com, sanjeevraut.4@gmail.com \\ ${ }^{2}$ Survey Officer, Nepal Electricity Authority, Nepal, pantashrijana@gmail.com \\ ${ }^{3}$ M.Sc. Student, Teri University, New Delhi, India, ftuladhar@gmail.com \\ 4Director, Land Management Training Center, Kavre, Nepal, janakrajioshi@hotmail.com \\ ${ }^{5}$ Lecturer, Kathmandu University, Nepal, nawa.shrestha@gmail.com \\ ${ }^{6}$ Instructor, Land Management Training Center, Kavre, Nepal, prashant127@hotmail.com \\ ${ }^{7}$ Managing Director, Genesis Consultancy (P) Ltd., Kathmandu, Nepal, anish.genesis@gmail.com
}

\begin{abstract}
A combination of rough topography, steep slopes, active tectonic and seismic process and intense impact of monsoon rain has made the fragile environment of Nepal vulnerable to a variety of natural hazards. Most frequent hazards are floods, landslides, epidemics, fires, earthquake and other hydro-meteorological disasters, causing heavy loss of human lives as well as economic loss including housing and infrastructures (MDRIP, 2009). Hence, hazard assessments are the need of the hour. They help district and regional decision makers, policy makers and development agencies prepare disaster risk reduction plans. The chosen study area was Banepa and Panauti municipality. Separate hazard assessments have been performed for four hazards, namely, earthquake, flood, landslide and industrial hazards.
\end{abstract}

Earthquake hazard zone maps have been made following the Probabilistic Seismic Hazard Assessment (PSHA) approach for 500 year return period to produce seismic intensity distribution maps in the form of Modified Mercalli Intensity (MMI) maps using Trifunac and Brady formula. Flood inundation maps have been made using HEC-RAS and HEC-GeoRAS extension for ArcGIS for return periods of 2, 10 and 500 of Chandeswori and Punyamata rivers. Landslide hazard susceptibility map has been made using the Stability Index Mapping (SINMAP) extension for ArcGIS that uses an infinite-slope equation accurate for debris flows. Industrial hazard maps that depict the vicinity that falls within various ranges of danger in the event of different industrial hazards like fire, Vapor Cloud Explosion (VCE) and Boiling Liquid Expanding
Vapor Explosion (BLEVE) have been prepared as well. Finally, a composite multi hazard map has been prepared by combining all the four hazards.

Keywords: earthquake, flood, landslide, industry, hazard assessment, composite multi-hazard

\section{Introduction}

Nepal is prone to various geological and hydrometeorological hazards owing to its diverse geographical coverage that includes rough topography, steep slopes and active tectonic and seismic processes.

The impact of multiple hazards has aggravated in recent years due to catalytic factors like climate change, rapid urbanization, and continual urban growth rates that result in high physical exposure and lack of preparedness both at national and local levels. In Nepalese context, mainstreaming disaster risk reduction efforts in municipal governance and development plans stills occupies low priority against other development plans. Further, the location of most urban cities in risk prone areas with loose networks of migrant populations increases the risk factor.

Multi hazard maps serve as guidelines to prepare effective disaster mitigation plans at local and national levels by depicting the intensity and probability of hazards in a given geographical location. M ulti-hazard maps of landslide, earthquake, flood and industrial hazards are first prepared to produce composite multi-hazard maps of $B$ anepa and Panauti. The resultant maps can help to identify the most vulnerable sectors and assist stakeholders to adopt necessary measures to increase resilience of the residents. 


\section{Study Area}

The study areas comprised of Banepa and Panauti municipalities of $\mathrm{K}$ avrepal anchok district. The spatial extent of Banepa municipality is between $27^{\circ} 37^{\prime} 01^{\prime \prime}$ to $27^{\circ} 39^{\prime} 03^{\prime \prime}$ north latitude and $85^{\circ} 30^{\prime} 45^{\prime \prime}$ to $85^{\circ} 32^{\prime} 52^{\prime \prime}$ east longitude geographically; and the spatial extent of Panauti municipality is between $27^{\circ} 33.5^{\prime}$ to $27^{\circ} 37^{\prime}$ north latitude and $85^{\circ} 29^{\prime}$ to $85^{\circ} 33.5^{\prime}$ east longitude.

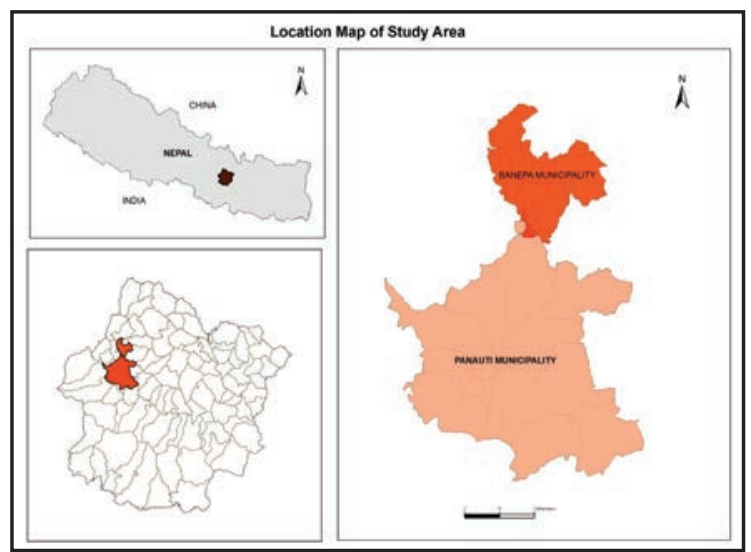

\section{M aterials U sed}

Datasets used for the project included socioeconomic data, Quickbird images at $0.6 \mathrm{~m}$ spatial resolution, geological map, $20 \mathrm{~m} D E M$, topographic map with $20 \mathrm{~m}$ contour interval, building inventory and land cover data along with Seismic Hazard $\mathrm{M}$ ap of $\mathrm{N}$ epal prepared by Department of $\mathrm{M}$ ines and Geology, 2002.

\section{M ethodology}

The general framework (Figure 1) adopted to prepare multihazard maps can be listed as:

- Preparation of earthquake hazard maps in form of PGA and M MI maps using PSHA approach.

- Flood depth and inundation maps for 2,10 and 500 year return periods using HEC-RAS and HECGeoRA S extension of A rcGIS.

- Generation of landslide hazard susceptibility map from SINMAP analysis and a GIS based spatial multi-criteria evaluation technique.

- Vector analysis to depict hazard indices for fire hazards, Vapor Cloud Explosion (VCE) and Boiling Liquid Expanding Vapor Explosion (BLEVE).

- Perform weighted sum to derive the final composite hazard maps that depicted the multi-hazard region.

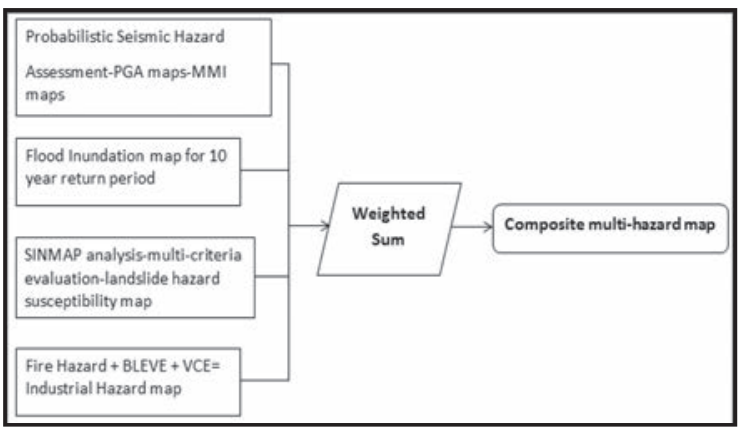

Figure 1: O verall method of multi-hazard mapping

A mong the different faults identified by The $N$ ational Building Code Implementation Project (1993), the (M ain Central Thrust) M CT 3.3 fault with potential 7.6 Richter scale was chosen for earthquake hazard mapping since it is the closest active fault that can generate the worst scenario earthquake for the study area.

PSHA approach was chosen to describe earthquake hazard in terms of the level of ground shaking that has a $10 \%$ chance of being exceeded in 50 years corresponding to a return period of 475 years.

First, the regional seismicity model is prepared based on an arbitrary scenario earthquake that occurs as a local earthquake. Next, attenuation model is created that represents the isoseismic contours at bedrock level and was generated using R.R.Youngs et.al, 1997 analysis followed by the site response model that describes how local geology affect the ground shaking experienced during an earthquake. The subsurface amplification values derived are used along with the attenuation model to produce surface Peak Ground Acceleration (PGA) maps. The PGA maps were modified to MMI maps using Trifunac and Brady 1975 relationship. The MM I maps are more intuitive and provide qualitative measure for earthquake intensity.

Flood hazard assessment consists of hydrologic/ hydraulic analysis; topographical analysis followed by feature creation from satellite image; steady flow simulation and further processing to delineate flood inundation and flood depth maps. Field discharge measurement and cross section survey were followed by TIN preparation from contours to obtain base layer; layers of river centerline, banks, flowpaths and cross-section were created by digitizing existing topographic data with simultaneous referral to satellite images, using RAS Geometry of HEC-GeoRAS extension in 
A rcGIS 9.3. Land-use map was used to extract the $M$ anning's $n$ value based on Manning's Roughness coefficient. Then, flow frequency analysis was computed from WECS/DHM (Water and Energy Commission Secretariat/Department of Hydrology and $\mathrm{M}$ eteorology) formula.

These preprocessed data were used as input for one dimensional Steady Flow Analysis in HECRAS which was run using the peak discharge value corresponding to the return periods flood event. The simulated HEC-RAS model was then visualized in ArcGIS environment through its HEC-GeoRAS extension using RAS mapping where: HEC-RAS export was used to define Flood Inundation extent followed by water surface generation. Finally, flood inundation and flood depth maps for 2, 10 and 500 year return periods were produced.

Due to the presence of eleven reliable landslides inventory in the study area, a deterministic method by using SINMAP model was used to prepare landslide susceptibility map where weights selected for multi criteria analysis are based on the report of (M HRA , 2011) and expert opinion. Semi-quantitative indicators have been used with resulting landslide susceptibility expressed in a scale from 0 - 10 for better representation of spatial variability. Only the final susceptibility was classified into qualitative classes of very low, low, moderate, high, and very high.

Eight indicators have been input to generate landslide hazard susceptibility maps. Three indicators were obtained from the SINMAP analysis and rests are obtained from secondary data. A spatial multi-criteria evaluation technique has been implemented in GIS system. Each indicator was processed, analyzed and standardized according to its contribution to hazard and percentage of existing landslide lies on different indicators. The indicators were weighted using comparison and rank-ordering weighing methods, and weights were combined to obtain the final landslide susceptibility maps. Eight thematic layers comprising from six conditioning factors and two triggering factors were created. The thematic layers were ranked into several classes from safe condition to the most prone condition for landslide hazard. Those layers are then combined with different values of weighting.

Different probabilistic mathematical calculations were performed for fire hazard map. A t first, buffer zones of 25, 50, 75 and $100 \mathrm{~m}$ were classified. The effects of thermal radiation on these zones were determined using mathematical formula. This produced different hazard intensity zones.

VCE and BLEVE were determined only for selected depots. Mathematical equations estimated the effective distances for VCE and BLEVE to be 120 and $80 \mathrm{~m}$ respectively. Following parameters were considered for assessing the impacts of fire hazard:

- Availability of fire brigade

-Fire spreading environment

- Fire fighting mechanisms

Then, the different degrees of hazard zone were determined and the building inventory data were overlaid to determine very high, high, medium and low vulnerability zones.

The produced hazard maps were used to prepare composite multi hazard map (Figure 2). For this, individual hazard maps were given values $1,2,3$ according to their output ranges for flood, landslide, industries and 2.5, 2.75, 3 for earthquake hazard maps. Weighted sum was done to derive the final composite hazard maps that depicted the multihazard region under three hazard regions, low, medium and high.

\section{Results}

The PGA distribution map for MCT 3.3 local earthquake scenario reveals that the municipal region would experience PGA range of 179 - 269 gal (i.e. $0.18 \mathrm{~g}-0.27 \mathrm{~g}$ ). For B anepa, the core municipal areas would experience PGA of 230 - 260 gal (Figure 2a). The core part of Panauti would experience PGA range of $230-260$ primarily due to its alluvial soil composition which amplify earthquake waves. The outskirts would face less PGA since the geological composition of residual and colluvial soils comparatively minify ground motion than alluvial soils. 


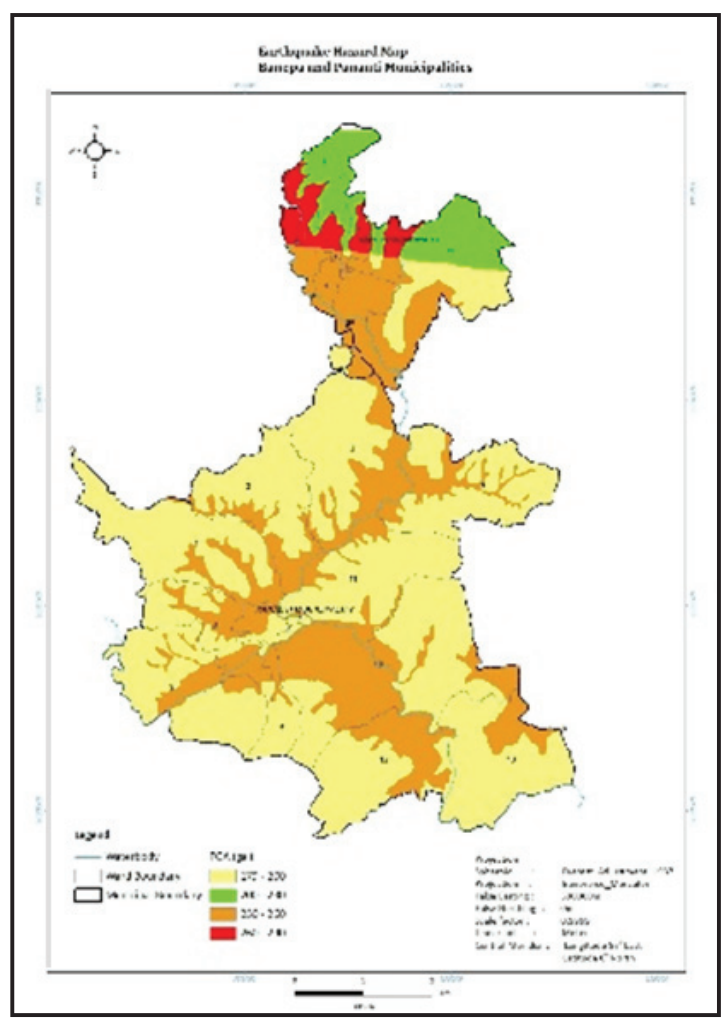

Figure 2a: PGA map

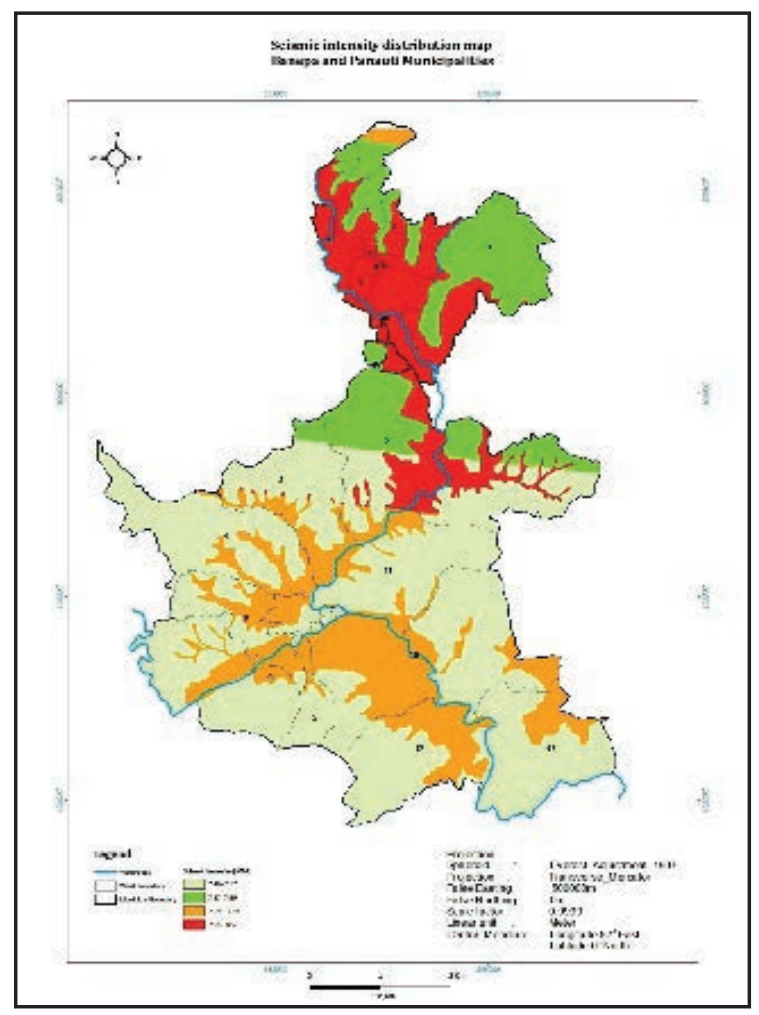

Figure 2b: Trifunac and Brady M MI map
The M M I maps reveal that the central and southern parts of B anepa fall within very high seismic hazard zone of $7.94-8.55 \mathrm{MMI}$. In contrast, only 165 hectares of Panauti fall under very high seismic zone but 2659 hectares cover the high hazard zone. Panauti is relatively less vulnerable with major region falling within the lowest range of $7.46-7.57$.

Flood inundation maps (Figure 3a) for 10 year return period (RP) show that 50.17 hectares and 0.389 hectares land fall under significant flooding region in Banepa and Panauti respectively. Flood depth was categorized into slight, moderate and significant depth based on specifications prepared by HAZUS. 25 buildings in B anepa were located in significantly vulnerable region compared to none in Panauti. The results obtained from landslide susceptibility maps (Fig 4b) are ranked from 35-450, which defines the landslide susceptibility from safe (very low) to very susceptible (very high). These maps further classified into five zones shows $5.16 \%$ of total land area nearly $34.5 \mathrm{sq} . \mathrm{km}$ falls under very high, $9.60 \%$ fall under high and $23.77 \%$ fall under moderate hazard index respectively.

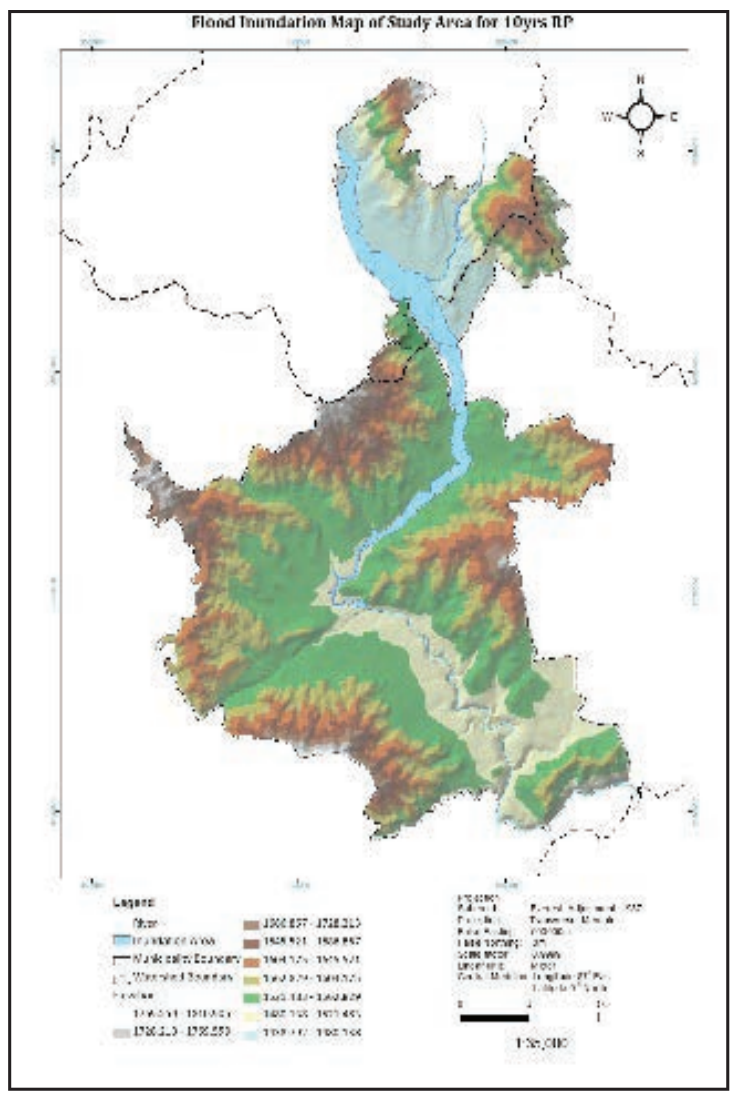

Figure 3a: Flood inundation map for $10 \mathrm{yr}$ RP 


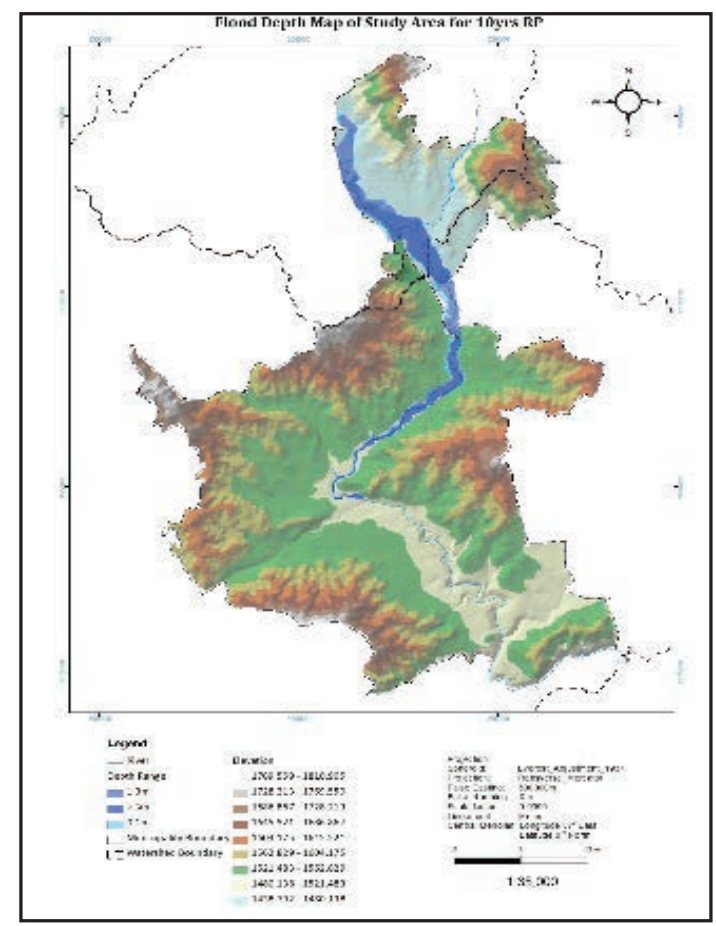

Figure 3b: flood depth map for $10 \mathrm{yr}$ RP

For industrial hazards, the chance for a fire accident is quite low due to less storage of inflammable materials and most buildings being RCC/RBC type. However, lack of abundant fire extinguishers/ brigades could even amplify a small fire.

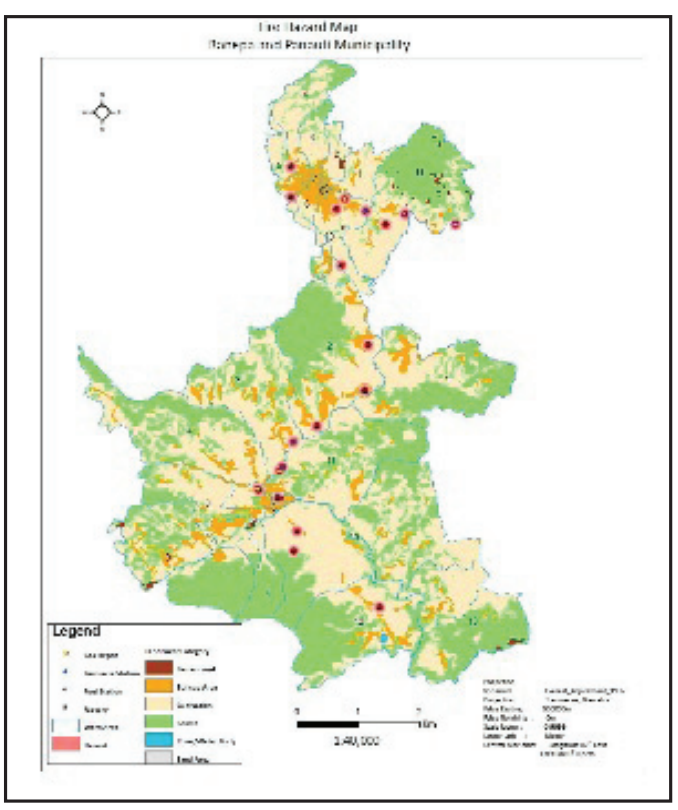

Figure 4a: Industrial hazard map

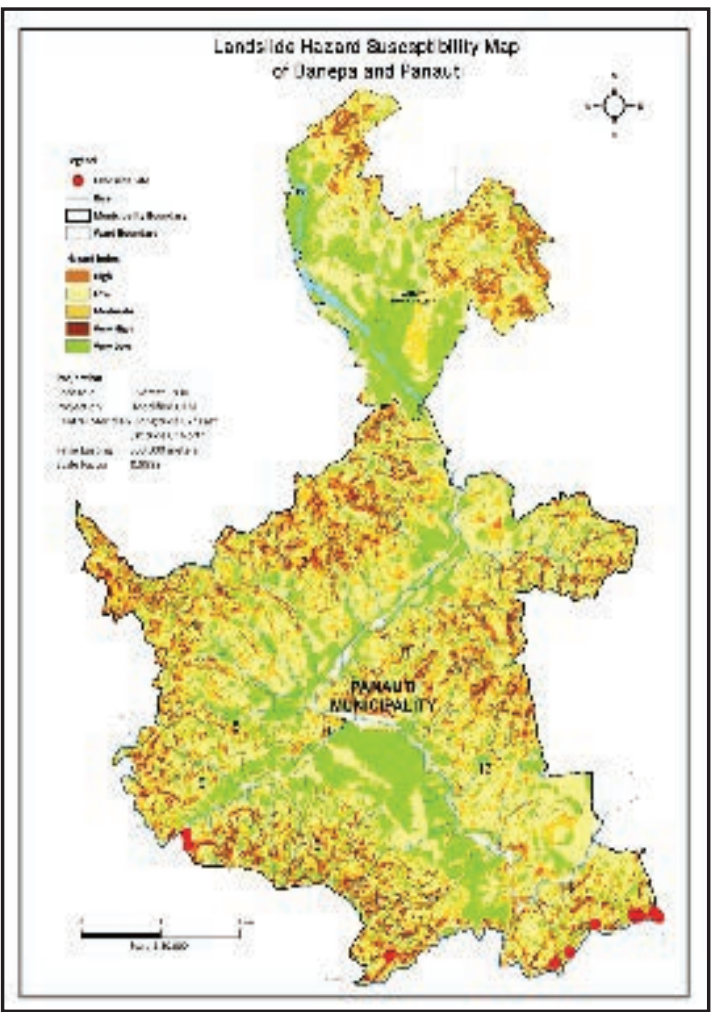

Figure 4b: landslide hazard susceptibility map

Probabilistic industrial hazard maps showing different hazard indices for fire hazards, VCE and BLEVE were prepared based on rapid assessment field survey done to summarize the status of industrial hazards and preparedness level. Fire hazards maps (Fig 4a) show very-high, high, medium, and low zones on the basis of heat achieved within selected buffer distances of $25,50,75$ and $100 \mathrm{~m}$ respectively.

\section{Conclusion}

Four hazard assessments were performed to produce hazard maps of three geological hazards namely earthquake, landslide, flood and one technological hazard- industrial hazard. The results include PGA distribution maps, M M I maps, landsl ide susceptibility maps, flood inundation, flood depth maps and industrial hazard maps showing the zones of different intensity or probability of certain hazard. The hazard maps have been used as a basis to calculate exposure statistics to predict the vulnerability scenario. This scenario has been used to study the vulnerability assessment.

The results of the research project suitably indicate that Panauti is more vulnerable to industrial and 
Iandslide hazards compared to Banepa. However, comparatively Panauti is less vulnerable to earthquake and flood hazards than B anepa. The hazard assessment performed could be used to formulate land use plans, disaster risk reduction plans in order to bolster our own adaptive capacity.

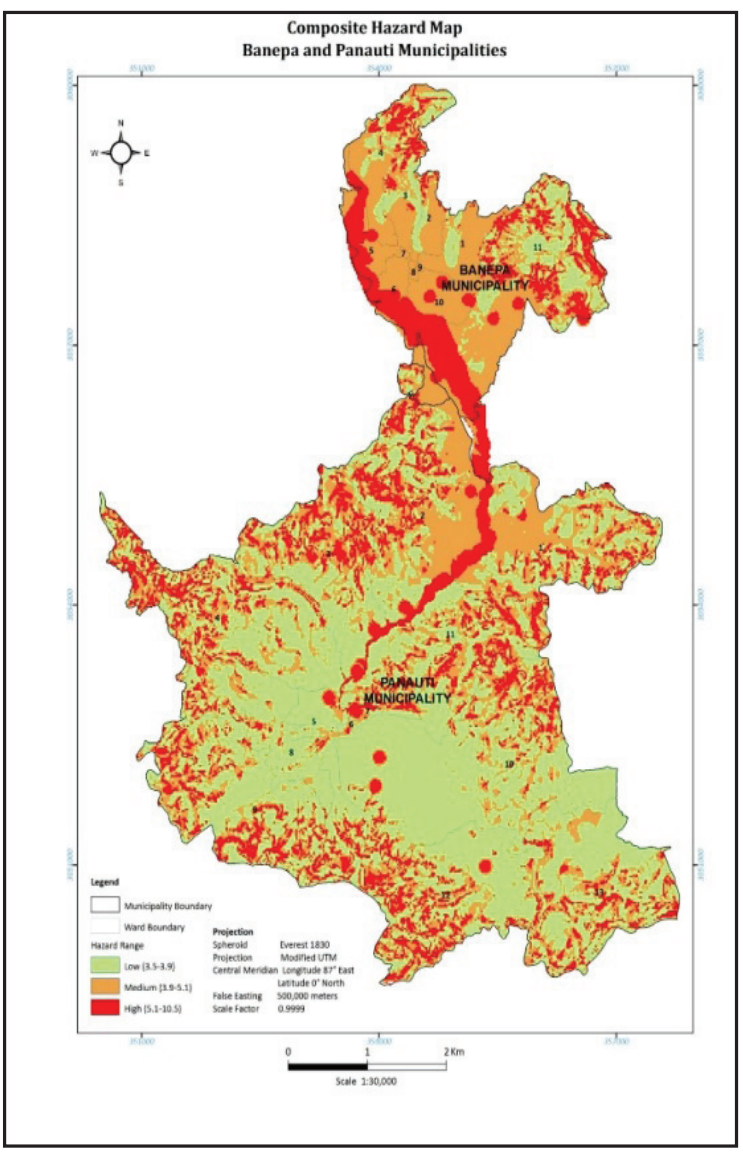

Figure 5: Composite Hazard Map of Banepa and Panauti Municipalities.

\section{Recommendation}

- Due to constant change of geospatial features over time, regular map updating and field validation are necessary to maintain validity, accuracy and reliability of the hazard maps.

- Landslide inventories need to be increased for accurate landslide hazard assessment and risk estimation

- More shear wave velocity measurements must be done to build a database of the site average shearwave velocities that can be used to verify, calibrate and possibly improve the original earthquake hazard maps.

- Liquefaction potential should also be considered to fortify earthquake hazard maps.

- Field cross-section measurement is recommended for better results in flood hazard assessment.

- Effect of wind direction and river presence could also be considered to enhance industrial hazard assessment.

\section{R eferences}

Bilham,R., Gaur,V.K., Molnar,P. (2001). EARTHQUAKES: Himalayan Seismic Hazard. Science 293.

Cameron T., A ckerman, P.E., 2011. HEC-G eoRAS GIS Tools for Support of HEC-RAS using ArcGIS U ser's Manual, Version 4.3.93,U.S. Army Corps of Engineers, Davis, California.

Desai, Dushyant, 2008, Industrial Risk Assessment for Planning and Emergency response: A case of Ahmedabad

Federal Emergency Management A gency, 2009b, HAZU SMH analysis levels.

HEC-RAS, 2009. Hydrologic Engineering Centers River Analysis System user's manual, U.S. Army Corps of Engineers, Davis, California.

I.D.Gupta. 2007.PROBABILISTIC SEISMIC HAZARD ANALYSIS METHOD FOR Mapping of spectral amplitudes and other design SPECIFIC quantities to estimate earthquake effects on man made structures. ISET J ournal of Earthquake Technology , p 127-167.

IFRC, 2000: World Disasters Report 2000: Focus on Public Health, International Federation of Red Cross and Red Crescent Societies, Geneva, IAEG Commission onLandslides (Secretary, D. M. Cruden), 1990: Suggested Nomenclature for Landslides, Bull., International Association of Engineering Geology, No. 41, pp. 13-17.

Joshi, A., Rakhal, B. \& Dawadi, G., 2012. Multi$\mathrm{H}$ azard Profile of $\mathrm{P}$ anauti M unicipality. Preparation of Risk Hazard Map of Panauti Municipality. In. K athmandu: Genesis Consultancy (P) Ltd. 
MHRA, 2011. Multi Hazard Risk Assessment in the Rakhine State of M yanmar, September 2011, part 1Hazard A ssessment, pp 49-50.

M ontgomery, D. R. and W. E. Dietrich, (1994). A Physically Based Model for the Topographic Control on Shallow Landsliding, Water Resources R esearch, 30(4): 1153-1171.

NHRA. (2010). Nepal Hazard Risk Assessment. Nepal.

Sales J aime, Wood M aureen, Jelinek Robert, 2007. Risk mapping of Industrial Hazards in New Member states, pp 18-19.
UNDP (2009). SDR Global Assessment Report on Poverty and Disaster Risk 2009.

UNDP (2009). SDR Global Assessment Report on Poverty and Disaster Risk 2009.

Varnes, D. J., 1978. Slope Movements, Types and Processes in Landslides, Analysis and Control, In Schuster R. L. and K rizek, R. J . (eds.), Special Report No. 176, TRB, National Academy of Sciences, Washington.

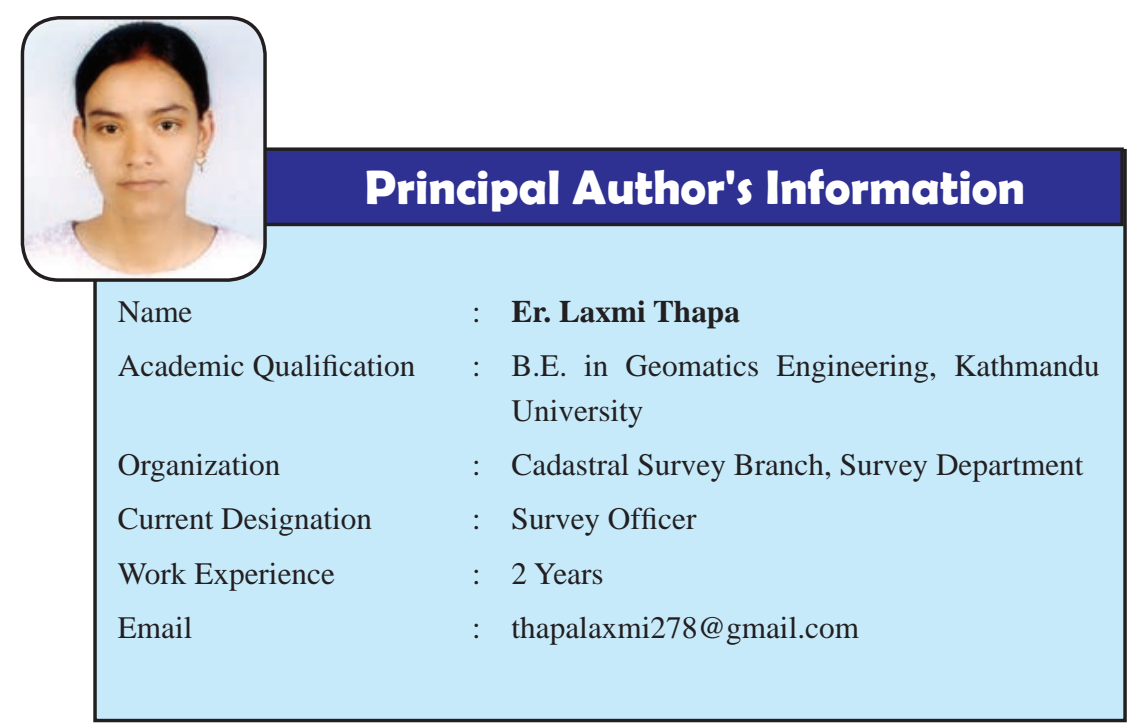

